\title{
EFFECT OF THE CONNECTIVE TISSUE SHEATH ON THE VALUE OF THE ACCOMMODATION CONSTANT $\lambda$ OF A NERVE FIBER
}

\author{
MASAYASU SATO* \\ Department of Physiology, Faculty of Medicine, Tokyo University, Tokyo
}

In the extensive studies on the accommodation curves, Solandt (13) briefiy mentioned that there was no remarkable difference in the value of the accommodation constant of nerves ( $\lambda$, Hill (2) and $\tau_{2}$, Monnier (6)), whether it was measured with intact nerves or desheathed nerves, while recently Suzuki (15) has reported that the $\lambda$ value was generally greater in the latter case than in the former. In connection with this problem it seems to be very interesting that the $\lambda$ value of the same preparation was different with the difference of the interpolar length $(4,12,13)$, of the value of the resistance of the circuit (12) and of the mode of stimulation (15). These problems seem to be very important for the following reasons: (i) whether the difference of the manner of stimulation and the existence-or-nonexistence of the epineurium affect the characteristics of the nerve fiber or not, and (ii) whether the epineurium of the nerve fiber has polarizability or not, as quite recently it has become the point of controversy between Rashbass and Rushton (8) and Lorente de Nó (5).

It is the purpose of this paper to present the results of the experiments dealing with these problems by measuring the accommodation curves of the nerve fiber under various conditions.

\section{METHOD}

Isolated single motor nerve fiber-muscle preparations of a Japanese toad were used exclusively. The circuits used and the methods of the measurement of the accommodation curves were approximately the same as those reported previously $(10,11)$. However, according to the purpose of the experiments the following slight modifications were adopted. In experiment (1), as diagramatically represented in fig. 1 , the central whole nerve part was mounted between $A$ and $B$, while between $B$ and $C$ the internodal stretch of the nerve fiber was mounted. The measurements were made in each case by switching the circuit over from one to the other, and in each preparation the interpolar length of the whole nerve part between $A$ and $B$ was changed in order to investigate the effect of it upon the accommodation constant, the distance between $B$ and $C$ being kept constant (0.5-0.6 mm.). In this experiment during the period when the measurements were being made between $A$ and $B$, the $B-C$ part was gener-

Received for publication January 26, 1952.

*佐藤昌氺 
ally short-circuited. In experiment (2), the whole nerve part was mounted between $A$ and $B$, as well as between $B$ and $C$, and the isolated single nerve fiber part was dipped in Ringer's pool of $C$ (11). In experiment (3), the internodal stretch of the nerve fiber was mounted between the two electrodes shunted with resistances of 5,30 or $60 \mathrm{~K} \Omega$ and on one and the same preparation the accommodation curves were measured with or without these shunting resistances (fig. 3 ).

The distance of the electrodes (between the edges of the glass plates) when the internodal stretch of the nerve fiber was mounted was generally about 0.5 or $0.6 \mathrm{~mm}$., while in the case. when the whole nerve part was mounted it was changed from 1 to $20 \mathrm{~mm}$. For measuring the accommodation curves of the nerve fiber, the exponentially increasing voltages of various time-constants were applied through the non-polarizable electrodes of $\mathrm{Zn}_{-} \mathrm{ZnSO}_{4}$-Ringer (agar) type, the twitch of the muscle being taken as an index of excitation of the nerve fiber. To check the change of the $\lambda$ value during the experiment, the measurements were generally made in such a manner that one series of determinations was inserted between the two other sets of determinations.

The experiments were performed in the summer, the room temperature then being $26^{\circ}$ to $29^{\circ} \mathrm{C}$. (experiment (1), (2)), and in the autumn $\left(19^{\circ}\right.$ to $21^{\circ} \mathrm{C}$., experiment (3)).

\section{RESULTS}

(1) Effect of connective tissues on value of $\lambda$. The $\lambda$ values, obtained on ten and several preparations, were between 2.95 and 8.94 msec. in whole nerve part stimulation, which will be denoted as $\lambda_{w}$, while they showed the value of $\lambda$ between 4.75 and $38.0 \mathrm{msec}$. in the case of a single nerve fiber part $\left(\lambda_{s}\right)$. Thus the latter values were generally larger than the former. An example of the accommodation curves measured with one and the same preparation is presented

Fig. 1. The circuit used for measuring the accommodation curves of the whole nerve part and the single nerve fiber part of the same preparation (upper figure) and examples of the accommodation curves obtained (lower figures). The stimulating current was generally descending. In the upper figure, $K$; mercury contact key, $r_{3} ; 2 \mathrm{k} \Omega, r_{4}$; variable resistance up to 1 $\mathrm{k} \Omega, r_{1}$ and $r_{2} ; 500 \mathrm{k} \Omega, c$; variable condenser up to $1 \mu \mathrm{F}$, and in lower curves the real line indicates the accommodation curve of the whole nerve part, while the broken line that of the single nerve fiber part.

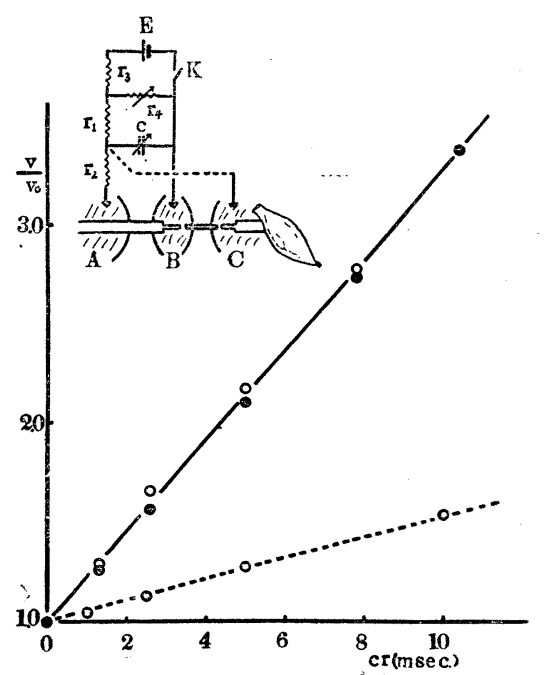




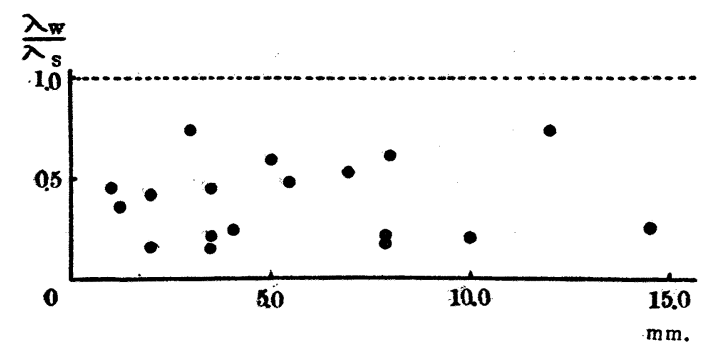

Fig. 2. Figures showing the relation of $\lambda_{w} / \lambda_{s}$ as plotted as an ordinate against the distance of the interpolar length as an abscissa. in fig. 1. In fig. 2 the ratio $\lambda_{w} / \lambda_{s}$ obtained on each preparation was plotted as an ordinate against the interpolar length as an abscissa, in which it may be clearly recognized that the value of this ratio is about 0.2 to 0.8 and it seems to be independent of the interelectrode distance. The difference in the value of $\lambda$ between two different modes of stimu-

lation of a nerve fiber is considered to be highly significant, because it is far larger than the experimental errors of about $10 \%$.

(2) Effect of interpolar length of whole nerve on value of $\lambda$. As was mentioned above, the whole nerve part was mounted between both of the two gaps, that is the $A-B$ and $B-C$ parts in fig. 1, the isolated single nerve fiber part being dipped in Ringer's pool of $C$, and on these two parts the accommodation curves were measured comparatively to see whether any different values might be obtained by the different interpolar lengths of the whole nerve part.

The results obtained are shown in table 1 , in which it may be seen that no systematic changes are found in the value of $\lambda$ with a difference of the length of the interelectrode stretch of from 1 to $20 \mathrm{~mm}$. Relatively a large difference

Table 1. Effect of interpolar length on $\lambda$ value

\begin{tabular}{|c|c|c|c|}
\hline $\begin{array}{c}\text { Prepartaion } \\
\text { No. }\end{array}$ & $\begin{array}{c}\text { Temperature } \\
\left({ }^{\circ} \mathrm{C} .\right)\end{array}$ & $\begin{array}{l}\text { Interpolar length } \\
(\mathrm{mm} .)\end{array}$ & $\begin{array}{c}\lambda \\
\text { (msec.) }\end{array}$ \\
\hline 1 & 26 & $\begin{array}{l}1.6 \\
\quad 5.5 \\
1.6\end{array}$ & $\begin{array}{r}6.7 \\
7.8 \\
23.8\end{array}$ \\
\hline 2 & 26 & $\begin{array}{r}13.0 \\
\downarrow \quad 1.0 \\
13.0\end{array}$ & $\begin{array}{l}7.7 \\
5.8 \\
7.7\end{array}$ \\
\hline 3 & 26 & $\begin{array}{r}20.0 \\
1.5 \\
20.0\end{array}$ & $\begin{array}{l}5.9 \\
5.9 \\
9.2\end{array}$ \\
\hline 4 & 27 & $\begin{array}{l}6.5 \\
1.5 \\
\quad 6.5\end{array}$ & $\begin{array}{r}45.0 \\
7.4 \\
5.7\end{array}$ \\
\hline 5 & 27 & $\begin{array}{l}2.5 \\
1.5 \\
2.5\end{array}$ & $\begin{array}{r}5.2 \\
11.4 \\
5.5\end{array}$ \\
\hline
\end{tabular}

of the $\lambda$ value during a set of experiments may be considered as the change of the $\lambda$ value, spontaneous or effected by the stimulation. Thus the results obtained in experiment (1) (fig. 2) and experiment (2) indicate the independency 
of the $\lambda$ value from the interpolar length of the whole nerve part.

(3) Effect of shunting resistance on $\lambda$ value. It can be easily understandable that, when stimulating a whole nerve part, connective tissues such as epineurium, endoneurium, indifferent fibers and Ringer's fluid around and in these tissues are effective as a shunting resistance for the active nerve fiber enveloped by them, so that to see whether any difference in the value of $\lambda$ might be obtained or not when the accommodation curves are measured with or without the shunting resistance outside a fiber,

Fig. 3. The circuit used for measuring the accommodation curves of the single nerve fiber with or without the shunting resistance $\left(\mathrm{r}_{s}\right)$, in which the notations are the same as those in fig. 1 except $r_{1}(100$ $\mathrm{k} \Omega$ ), and an example of the accommodation curves, in which circles represent those without the shunting resistance, white triangles that with $30 \mathrm{k} \Omega$ and black triangles with $60 \mathrm{k} \Omega$.

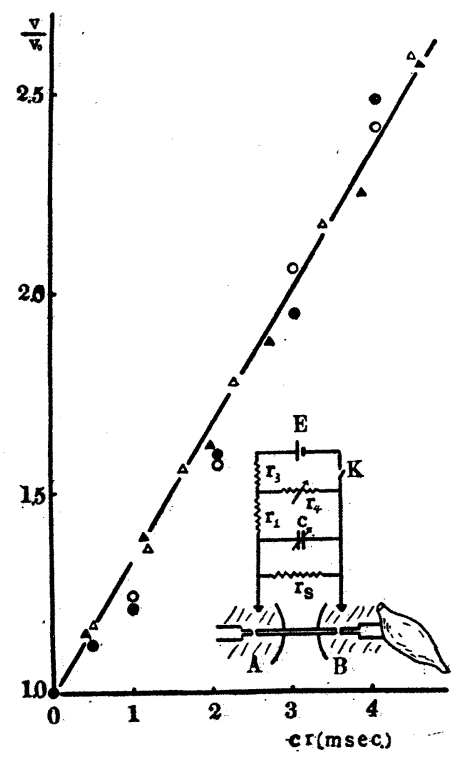

Table 2. Effect of shunting resistance on $\lambda$ value

\begin{tabular}{|c|c|c|c|}
\hline $\begin{array}{c}\text { Preparation } \\
\text { No. }\end{array}$ & $\begin{array}{c}\text { Temperature } \\
\cdot\left({ }^{\circ} \mathrm{C} .\right)\end{array}$ & $\begin{array}{c}\text { Shunting resistance } \\
(\mathrm{k} \Omega)\end{array}$ & $\begin{array}{c}\lambda \\
\text { (msec.) }\end{array}$ \\
\hline 1 & 21 & 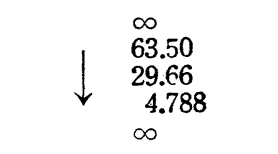 & $\begin{array}{l}6.40 \\
5.00 \\
6.05 \\
6.45 \\
5.20\end{array}$ \\
\hline 2 & 21 & 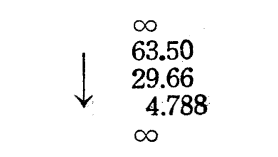 & $\begin{array}{l}4.55 \\
5.40 \\
5.88 \\
5.85 \\
4.10\end{array}$ \\
\hline 3 & 19 & $\begin{array}{ll} & \infty \\
& 63.50 \\
& \infty \\
29.66 & \infty\end{array}$ & $\begin{array}{l}4.55 \\
5.40 \\
5.85 \\
5.85 \\
4.10\end{array}$ \\
\hline 4 & 20 & $\begin{array}{l}63.50 \\
\infty \\
63.50 \\
4.788 \\
\infty \\
4.788 \\
29.66 \\
\infty \\
29.66\end{array}$ & $\begin{array}{l}6.96 \\
7.50 \\
7.80 \\
7.25 \\
7.25 \\
7.50 \\
8.60 \\
8.70 \\
8.70\end{array}$ \\
\hline
\end{tabular}

may be considered as being an important key for explaining the results (1) and 
(2). In the usual case, as the ohmic resistance of the sciatic nerve was about $20 \mathrm{k} \Omega$, the resistance of 5,30 or $60 \mathrm{k} \Omega$ was connected in parrallel with the nerve fiber. In fig. 3 and table 2, examples of these measurements are presented, in which it may be found that the value of $\lambda$ is approximately the same despite the existence of the resistance and that it is also independent of the value of these resistances. The difference of about $10 \%$ in the measured values in table 2 may be considered to be due partly to the change of $\lambda$ value during a set of experiments and partly to the experimental errors.

\section{DISCUSSION}

From the results of experiment (3), it may be understandable that the reason why $\lambda_{w}$ is smaller than $\lambda_{s}$ is not attributable to the fact that the connective tissue is a simple ohmic resistance for the active nerve fiber, but to the existence of the capacitative element in this tissue, which means that, when a current traverses it, the time-course of the exponentially increasing current applied may be distorted or becomes slower. Consequently, for the excitation of the nerve fiber covered with a connective tissue, a current of shorter time-constant and greater intensity is necessary than in the case of an isolated single nerve fiber, resulting in a smaller value of $\lambda$ in the former case. Furthermore, the reason why the value of $\lambda$ is not different regardless of the difference of the interpolar length may be attributed to the possible fact that the current will be distorted when it traverses the connective tissue. On the other hand, when it flows through the nerve longitudinally there is only a pure ohmic resistance in the nerve.

The results of Laugier (4) and Schriever (12), contradictory to the results mentioned above, that the accommodation constant ("Einschleichzeit" (12)) of the whole nerve increased with the increase of the outer resistance and with that of the interpolar length might be attributable to some experimental failures. In reality, Hill, Solandt and Katz (3) already found that the $\lambda$ value did not change appreciably with the change of the interpolar length. The plausible explanations of Laugier's and Schriever's misleading conclusions may be considered to be due to the following alternative facts: (i) the difference of the $\lambda$ values which they reported are too small (about a few per cent of the $\lambda$ value) to be considered significant and may be considered to be in the range of experimental errors, or (ii) as they used a whole nerve, it might be possible that the index taken might have changed from a fiber to another during a set of experiment (11). Also it is a probable fact that Suzuki's results which indicated the change of the $\lambda$ value with the change of the different mode of stimulation or with that of the electrodes used (14) may be attributable to an unconscious polarization in the electrodes.

It is uncertain to conclude only from these results mentioned above whether such an appreciable polarizability exists in the epineurium or in the indifferent fiber groups. However, it is certain that there is a marked difference in the response to the electrical stimulation of an isolated nerve fiber and a fiber covered with the connective tissues including indifferent fibers. This conclusion is 
very important because of the facts that the results obtained with the electrical stimulation of a whole nerve and the action potentials recorded from the surface of an intact nerve must be explained by considering the marked polarizability of the connective tissues.

An important question may arise, as has been done by Lorente de Nó (5), whether the properties of a nerve fiber have changed after it was isolated, or not. However, in this experiment there are some facts to be believed that the properties of an isolated nerve fiber did not change appreciably during an experiment of several hours. It may be necessary to present here as evidences for this only the facts that the threshold of the nerve fiber was kept constant throughout an experiment in the range of about several per cent when it had been isolated under good conditions and that $\lambda_{s}$ is not smaller than $\lambda_{w}$. The reason of this is because, as has been confirmed by Rosenblueth (9) and Parrack (7), an excised nerve shows faster accommodation than that with circulation intact, so that if the fiber become weakened by the procedure of isolation it may be a probable fact that the threshold would become higher gradually and the accommodation constant smaller.

Thus we can exclude such an argument as that proposed by Lorente de Nô (5) as being insignificant and conclude the existence of the marked polarizability of the connective tissues, considering Suzuki's results already mentioned (15). However, the time-constant of a nerve to traversing current (about 0.2 msec.), which has been obtained by Davis and Lorente de Nó (1) by recording the electrotonic potential, is too small to explain such a marked decrease of the $\lambda$ value of a nerve fiber when it is covered with connective tissues. This may perhaps mean the inadequacy of this value and of the method of recording the electrotonic potential from a surface of an intact nerve. It is necessary to calculate this value from the record obtained by inserting an electrode into a whole nerve or to determine it from a dissected epineurium.

\section{SUMMARY}

It has been found that the value of the accommodation constant $\lambda$, measured with the isolated single nerve fiber part, was generally larger than that with the whole nerve part of the same preparation and that the $\lambda$ value was independent from the interpolar length of the whole nerve part. For explaining these results, the $\lambda$ value of the fiber with the parallel shunting resistance of several $\mathrm{k} \Omega$ and that without it were comparatively measured and they were found to be almost the same. These results indicate the high polarizability of the connective tissues, which distorts the applied current, resulting in a smaller value of $\lambda$. Thus it may be concluded that the connective tissue is polarizable for the transverse current, while it is only an ohmic resistance for the longitudinal current.

I am indebted to Dr. Ichiji Tasaki for his helpful advices aud criticisms.

\section{REFERENCES}

1. DAVIS, L. AND LORENTE DE NÓ, R. Contribuiton to the mathematical theory of electro- 
tonus, IX Chapter of Lorente de Nós "A study of nerve physiology." New York: Rockefeller Institute for Medical Research, 1947.

2. Hill, A. V. Proc. Roy. Soc. Lond. B. 119 : 305-355, 1936.

3. Hill, A. V., Katz, B. And Solandt, D. Y. Proc. Roy. Soc. Lond. B. 121 : 74-133, 1937.

4. Laugier, H. Electrotonus et excitation. Paris: Paul Marmy, 1921.

5. LORENTE DE No, R. J. cell. comp. Physiol. 35: 195-240, 1950.

6. Monnier, A. M. L'excitation èlectrique de tissue. Paris : Hermann, 1934.

7. Parrack, H. O. Am. J. Physiol. 130: 481-495, 1940.

8. Rashbass, C. ANd Rushton, W. A. H. J. Physiol. $110: 110-135,1949$.

9. Rosenblueth, A. Am. J. Physiol. 132 : 99-118, 1940.

10. SATO, M. Jap. J. Physiol. 1 : 309-315, 1951.

11. Sato, M., Nadao, M., Terauchi, C., Yamanaka, T. and Matsumoto, M. Jap. J. Physiol. 1 : 256-263, 1951.

12. SCHRIEVER, H. Z. Biol. 93 : 123-148, 1932.

13. Solandt, D. Y. Proc. Roy. Soc. Lond. B. 119 : 355-379, 1936.

14. Suzuki, M. Pfl. Arch. ges. Physiol. $239: 81-96,1937$.

15. Suzuki, M. Communicated at the 28th general meeting of the Jap. Physiol. Society, 1951. 